\title{
Idling Emission at Intersection and Exploring Suitable Mitigation Measures
}

\author{
Ravindra Kumar \\ CSIR-Central Road Research Institute, Transportation Planning Department, CRRI, Mathura Road, New Delhi, India \\ Email: ravindra261274@gmail.com \\ Purnima Parida, Devesh Tiwari, and S. Gangopadhyay \\ CSIR-Central Road Research Institute, Transportation Planning Department, PED, Director CRRI, Mathura Road, New \\ Delhi, India \\ Email: \{punam31, Devesht31\}@gmail.com, sgp.crri@nic.in
}

\begin{abstract}
Variety of road based transport modes catering to the transport demand ply in large number on the road system of urban India. As a result, the traffic and transportation problems are aggravating day by day. These problems manifest in the form of increased traffic congestion, increased air and noise pollution, accidents, delays etc. The consumption of fuel is on the increase due to enhanced trip lengths, shift of modal share towards personalized modes of travel and at signalized intersections due to idling of vehicles during stoppage phases. The results of a study conducted by CRRI in 2005 estimated that fuel worth of Indian Rupees. 1, 0000 Million is wasted every year in Delhi by vehicles idling at 600 signalized traffic signals and was around $15 \%$ of the total fuel consumed annually in Delhi. In addition, the time loss to the commuters is also associated with the delays. The running engines during idling also generate emissions, which are harmful both for human health and ecology. One of the ways to conserve fuels is to minimize its wastage. It is necessary to understand the amount of fuel loss and emissions generated at signalized intersections in the country. By applying various engineering / management measures the fuel wastage and associated emissions can be reduced. Presently there is no model that can give the amount of fuel loss and emissions in relation to the type of vehicle and delays. In this paper a review of the study for exploring suitable mitigation measures to improve the signalized intersections are presented.
\end{abstract}

Index Terms-Idling emission, fuel loss, intersection, suitable exploratory measures, Delhi, Vehicle,

\section{INTRODUCTION}

Motor vehicles are one of the major contributors to greenhouse gas emission inventories. Understanding the relation between vehicle emissions at intersection and exploring suitable mitigation measures is an important step toward reducing the potential for global warming, smog, ozone depletion, and respiratory illness [1]. On roads vehicles contribute substantially to national and local emissions of CO, HC, NOx, and PM [2]. Stopping at signalized intersections is defined as idling in a short period of time.

Manuscript received January 5, 2013; revised February 28, 2013.
There is continuous increase in fuel consumption in metropolitan cities due to increased trip lengths, shift of modal share towards personalized modes of travel and congested intersections. When the vehicles are waiting for their turn to clear the intersection, the drivers normally keep the engines of their vehicle on and this result in extra fuel consumption. Small amount of fuel wasted, aggregated over number of cycles per day, number of days per month and number of signalized intersections becomes a huge quantity. In CRRI report [3] fuel loss everyday during idling of vehicles was reported 0.37 million kilograms of $\mathrm{CNG}, 0.13$ million litres of diesel and 0.41 million litres of petrol. Converting these figures into monetary terms, the total losses work out to be Rs.27.25 million per day and Rs.9944.5 million per annum. After the implementation of remedial measures, a total of 67.78 per cent of fuel savings and a 71.12 per cent savings in the economic loss accrued [4]. Therefore, many researchers have been carried to explore the suitable mitigation measures all over the world.

\section{ESTIMATION OF REDUCTION IN FUEL LOSSES}

Chen Kun and YU Lei [5] developed an integrated microscopic traffic-emission simulation platform for estimating vehicle emissions, which can capture the instantaneous vehicles' modal activities, and quantify the relationship between motor vehicles' exhaust emissions and vehicles' operating modes. Their study illustrated that vehicles' emissions are strongly dependent on vehicles' operating modes, especially during acceleration. Further, different instantaneous speeds and accelerations result in different traffic emissions. The impacts of different traffic control strategies on traffic emissions are analyzed. Kumar et al. [6] reported that vehicle emission is highly dependent on local driving cycle, hence local road, traffic, vehicle and their delay and driving pattern affect the vehicle emission significantly.

Delays are imminent at the crossings to avoid conflicts, because of the time-sharing nature of the traffic control devices. To reduce delays various traffic engineering and management measures are employed at the intersections like; construction of flyovers and interchanges, turning 
movement restrictions, optimization of cycle timings, widening of roads, and synchronized traffic signals.

Parida and Gangopadhyay [4] applied engineering/management measures at the selected 12 intersections, to estimate the savings in delays and on the basis of the savings accrued at low, medium and high volume intersections the savings at the total signalized intersections was estimated, assuming similar kind of remedial measures. Their study reported a total of 67.78 per cent of savings in fuel wastage and 71.12 per cent savings in the economic loss due to fuel loss is expected to be accrued. Table I presents the Annual fuel loses and monetary losses at signalized intersections in Delhi. It is evident from the Table that 13,58,69,632.0 Kilograms of CNG, 4,73,57,100.2 Litres of Diesel, 14, 784, 05, 94.7 Litres of Petrol worth Rs. 9945 Million is being wasted at the signalized intersections of Delhi during idling of vehicles.

TABLE I. LOSS OF FUEL DUE TO IDLING OF VEHICLES AT SIGNALIZED INTERSECTIONS IN DELHI

\begin{tabular}{|c|c|c|c|c|c|}
\hline \multirow[b]{2}{*}{$\begin{array}{l}\text { Intersect } \\
\text { ion }\end{array}$} & \multirow{2}{*}{$\begin{array}{c}\text { No. of } \\
\text { Intersecti } \\
\text { ons }\end{array}$} & \multicolumn{3}{|c|}{ in litres } & \multirow{2}{*}{$\begin{array}{c}\text { Miilli } \\
\text { on } \\
\text { Rs. }\end{array}$} \\
\hline & & $\mathrm{CNG}$ & Diesel & Petrol & \\
\hline Low & 69 & $\begin{array}{r}8387157 . \\
6\end{array}$ & $\begin{array}{r}1354699 . \\
7\end{array}$ & $\begin{array}{r}7570698 . \\
5\end{array}$ & $\begin{array}{r}504.1 \\
8\end{array}$ \\
\hline Medium & 118 & $\begin{array}{r}17747734 \\
.1 \\
\end{array}$ & $\begin{array}{r}498268 \\
2.5 \\
\end{array}$ & $\begin{array}{r}18146889 \\
.3 \\
\end{array}$ & $\begin{array}{r}1215 . \\
58 \\
\end{array}$ \\
\hline High & 413 & $\begin{array}{r}109734 \\
740\end{array}$ & $\begin{array}{r}410197 \\
18\end{array}$ & $\begin{array}{r}12212300 \\
6.9\end{array}$ & $\begin{array}{r}8224 . \\
93\end{array}$ \\
\hline Total & 600 & $\begin{array}{r}135869 \\
632 \\
\end{array}$ & $\begin{array}{r}473571 \\
00.2 \\
\end{array}$ & $\begin{array}{r}14784059 \\
4.7\end{array}$ & $\begin{array}{r}9944 . \\
69\end{array}$ \\
\hline
\end{tabular}

In another research by Suresh Pandiana, Sharad Gokhale, Aloke Kumar Ghoshal[7] reported the effects of traffic and vehicle characteristics on vehicular emissions near traffic intersections to understand the a link between emissions and the most likely influencing and measurable characteristics. In their paper, the relationship of traffic, vehicle and intersection characteristics with vehicular exhaust emissions and with reference to the traffic flow and emission models was developed. They concluded that vehicular exhaust emissions near traffic intersections are largely dependent on fleet speed, deceleration speed, and queuing time in idle mode with a red signal time, acceleration speed, queue length, traffic-flow rate and ambient conditions. The vehicular composition also affects emissions. These parameters can be quantified and incorporated into the emission models. They found to quantify some non-measurable parameters such as driving behaviour, pedestrian activity, and road conditions was challenging task in absence of any validated methodology.

A number of factors based on the characteristics of traffic, vehicles, and street configurations are found to affect vehicular exhaust emissions. These characteristics have a cumulative effect on exhaust emissions. Most studies concentrated on limited parameters of the characteristics such as, driving speed and modes of traffic characteristics, road grades of road characteristics, and driving pattern, vehicle characteristics.
A few studies critically assessed the impacts of the existing control strategies and suggested that renewal of fleets, exclusive separate lane for buses, land use and traffic planning regulations may improve the air quality in urban areas. However, the lack of proper methodology in estimating emissions at traffic intersections, which incorporates all dynamic parameters, has slowed down the advancement in emission modelling for such locations. As a result, dispersion modelling has also been affected by a greater amount of uncertainties. Existing models moreover do not incorporate the traffic-flow calculations and vice versa. It can be perceived that emission and flow models can be combined together for better estimates of emissions and may further be integrated with the urban transportation and air quality planning system.

ZHANG Yingying, CHEN Xumei, ZHANG Xiao, SONG Guohua, HAO Yanzhao, and YU Lei [8] assessed the effect of traffic signal control strategies by integrating the microscopic traffic simulation model of VISSIM and the VSP-based approach of emission modeling, their research was a development of an integrated microscopic simulation platform of traffic emissions, which was finally used to evaluate the impact of two traffic control strategies, alternative signal timing and traffic flow on emissions. Based on a review of literatures, In this research study collected and categorized the different exploratory suitable mitigation methods to reduce the emission and fuel under control strategies as follows.

\section{EXPLORATION OF VARIOUS SUITABLE MITIGATION MEASURES}

\section{A. Coordination and Optimization of Signal Time}

Traffic signal timing improvement is the most widespread congestion management practice in the United States[9]. Signal timing improvements can include simple changes in timing plans or complex computercontrolled signal coordination along an entire corridor. As a result of effective signal timing improvement, congestion is reduced, safety is increased, and the amount of emissions released to the air is also reduced. In a study conducted in Atlanta, significant reduction in $\mathrm{CO}$ emissions was observed when the traffic signals were coordinated [9]. Another study suggests that acceleration produces the highest emission rate, whereas idling produces a lower rate. Therefore, efforts aimed only at reducing stop time may not always be successful in achieving overall reductions in air pollution emissions. Lei Yu, Fengxiang Qiao, and Fatemeh Soltani [10] [11] study also suggests that coordinated signal timing improves traffic flow, which leads to reduction in vehicle emissions and moderate improvements in Level of Service (LOS). Chen Kun and Yu Li [5] reported that the optimization of signal timing plan can improve the traffic operations as well as reduce the traffic emissions

ZHANG Yingying, CHEN Xumei, ZHANG Xiao, SONG Guohua, HAO Yanzhao, YU Lei[8] assessed the effect of traffic signal control strategies on vehicle emissions in Beijing. They collected and compared the real world emissions under signal coordination and noncoordination in Beijing city, and analyze the emission 
levels and distribution characteristics under these two control strategies. Their study reported that in comparison with the emission factors of non-coordinated road, the $\mathrm{HC}$ and $\mathrm{CO}$ emission factors of coordinated signal controlled road decreased by $50 \%$ and $30 \%$, but NOx increased by $10 \%$. The result showed that using signal coordination can effectively reduce $\mathrm{HC}$ and $\mathrm{CO}$ emissions, but increase NOx pollution.

All emission rates under acceleration are very high. Therefore, the emission under acceleration should be strictly controlled. It was found that the emission factors increased by about $10 \%$, the travel time increased by $5 \%$, and the average speed dropped by $5 \%$ after the coordinated signal controlled road was converted to noncoordinated road. The result indicates that the optimization of the traffic signal control plan can effectively improve the operation of road traffic and reduce factors significantly decreased respectively, as much as over $50 \%$. The maximum reduction was NOx, up to $78.32 \%$, which indicates that the decreasing traffic demands can significantly reduce vehicle emissions. Therefore, when selecting traffic management and control strategies to control emissions on-roads, traffic managers can consider implementing the optimization of signal timing, and at the same time try to control traffic demands.

\section{B. Strategies to Conserve Fuel through Increased Patronage of Public Transportation System}

The public transport creates a better and safer environment in the cities by reducing congestion, pollution and provides more efficiently, less costly and minimal energy solution to the Urban Transport problems. The measures such as reservation of separate bus lanes/bus ways on major arterials, provision of bus priority signals, encouragement of battery operated buses, introduction of premium bus services, enhancement of private participation to bring capacity augmentation and price discrimination etc. are to be taken to strengthen the road based public transport and to induce the individual vehicle owners to use the public transport.

CHEN Kun \& YU Lei [5] analyzed the impacts of different traffic control strategies on traffic emissions. They reported that setting bus exclusive lane can improve the traffic operation of the roads in the study network, and reduce the emissions of $\mathrm{CO}, \mathrm{HC}$, and NOx of buses respectively by $2.58 \%, 5.02 \%$, and $2.67 \%$. However, setting bus exclusive lane increases the $\mathrm{CO}$ emissions of cars and LGVs, by $13.26 \%$ and $16.52 \%$. Optimization of signal timing plan was suggested to improve the traffic operations as well as reduce the traffic emissions. In summary, some traffic control strategies which are used to improve the traffic operations may increase traffic emissions. Therefore, the implementation of traffic control and management strategies should consider not only mitigating the traffic congestions, but also reducing the traffic emissions.

For a sustainable development, the endeavour has to conserve the fast depleting fuel reserves. One of the ways to conserve fuels is to minimize its usage and wastage. The strategy to decrease the demand for motorised modes is one of the measures to reduce the fuel consumption. This can be achieved by promoting the patronage of public transport modes and non-fuel wasted at the signalized intersections, which is approximately 15 per cent of the total fuel consumed in the transport sector in Delhi. It is despite the fact that Delhi has around 16 per cent of its area under transport land use and traffic movement is quite streamlined and well managed. Many a large cities and majority of medium sized cities in India do not enjoy these privileges and it implies that the percentage of fuel wastage in these cities will be certainly more than the fuel wasted in Delhi.

\section{Land Use \& Transport Policy}

A move towards sustainable urbanism, matched with the use of sustainable technologies (vehicle and fuels), is critical to arrest the increased dependence on fossil fuels and the escalating air-pollution at both the local and global scales. An approach towards sustainable urbanism, besides requiring a strong emphasis on land use and transport integration, demands the attainment of a certain level of urbanity through place-making.

Urban transportation problems have stemmed from a number of factors. The most dominant single factor is the improper planning and development of cities and the corresponding transport systems and their management. The city planners have limited their tasks to mere land use planning with little or no cognizance for transport system that is to serve the proposed land use developments. Besides this, most of the cities have grown traditionally as mono-centric cities with old narrow roads to perform the function of arterial roads. The spatial separation of work places and education centers with residential areas, culminate in enhanced trip lengths resulting in increased journey time on city roads. This has a direct bearing on the energy usage and hence emissions. Given the present land use configuration and the economic and demographic characteristics of the population, travel demand is expected to remain high.

The long-range outlook will undoubtedly lead to changes in land use. There is consequently a need for long term urban planning aimed at the development of integrated communities combining residential activities with industrial and commercial activities. Many of the long distance motorized trips made currently for work, business or shopping could be converted to short distance walk and non-motorized mode trips. Some of these trips could be as well be substituted by telecommuting.

Reena Tiwari, Robert Cervero, and Lee Schipper [12] adopted $\mathrm{CO} 2$ reduction by Integrating Transport and Urban Design strategies for Australia for sustainable development.. They suggested DDD of sustainable urbanism (density, diversity, and design) forwarded by Cervero, when combined with Schipper's ASIF identity to estimate the components of travel that yield emissions (Schipper, Marie, \& Gorham, [13]) and the more recent ASIF2 paradigm (avoid, shift, improve and finance) to address changes in these components that reduce emissions, provide a coherent framework for the development of a sustainable green town: Bentley Technology Precinct(BTP), located in the car-oriented 
city of Perth. The success of the outcome was measured by undertaking an audit for place-making, VKT and CO2 reductions. Findings showed the three scenarios for VKT and $\mathrm{CO} 2$ reduction. The light rail scenario, although exceedingly expensive, had a similar reduction of carbon emissions as the bus-based scenarios; however, its placemaking contribution is immense. BRT is a cheaper alternative to light rail and serves the same purpose.

However, the key to its success is achieving a high patronage to reduce the overall carbon footprint per rider, as well as running costs. Furthermore, part of its success is making public transport appealing to the masses and user-friendly, which could be achieved by a public relations campaign and making improvements to the BRT to make the journey quicker than private vehicles.

They addressed many challenges to be successful.

These include:

Land acquisition implications with regards to financial and potential political costs.

Maintaining a balance of stakeholders' interests in the precinct.

Housing provision for a balanced demographic mix (students and workers). Failure to do so will mean that travel savings from living close to work and/or study for particular demographics will be lost and will result in a loss of diversity for the precinct.

Reducing traffic in a location served by high capacity roads, which has large numbers of through traffic and will lose road width due to on-street parking and nonautomotive priority lanes.

Shift in travel behaviour in a population used to travelling by car by shifting the current perception of public transport as unsafe, time-consuming and inconvenient.

\section{Restraints on Motorized Traffic}

Restraining motorized traffic indirectly provides priority and preference to NMT modes in the traffic system operation. Through transportation system Management (TSM) techniques entry to congested areas and central business districts by motorized modes should be restricted permitting only public transport modes andnon-motorized modes. The motorized private modes should be taxed by way of road user charges and parking fee in the congested areas.

Reena Tiwari et al., [12] reported about Perth which is a car dependent city. Pert city cannot afford to continue on this path according to a Business As Usual model. Car dependence not only contributes to greenhouse gas emissions but also has social ramifications, such as inequalities of access affecting the quality of life of those disadvantaged by this. It also makes public transport less attractive, especially where journeys are quicker by private car. This is why the Master Class investigated strategies, including ASIF2 paradigm (avoid, shift, improve and finance) and DDD (density, diversity and design) model, which could be applied to Perth in order to create a more sustainable city, particularly in the Bentley Technology Precinct. The ASIF2 paradigm provides an opportunity to avoid car dependence and carbon emissions in Perth. It is a perfect model that can be applied to Perth to show the impacts that changes in land use, transport and other forces have on vehicle movements and consequently, on carbon emissions. The ASIF2 would be facilitated by planning residential and commercial development in areas well serviced by transport infrastructure and amenities as opposed to mono-cultural suburbs which have amenities that realistically are only accessible by car. The strategy of urban infill provides the opportunity of mixed uses and higher densities. This is particularly the case in established areas that already have infrastructure and amenities in place, which can be utilised by future development.

\section{E. Encouraging Non-Motorized Modes}

Since India's independence, governmental planning and policies have followed the models adopted by developed countries in which development is equated with mechanization and non-motorized transport modes are considered a 'nuisance' in the urban transport system. This approach is in contradiction to the reality of the Indian conditions. India is a developing country with low reserves of fossil fuels and depends heavily on oil imports It also faces the shortage of foreign exchange reserves and capital resources but is rich in manpower resources.

These modes are an essential part of the sustainable and suitable transport modal mix for Indian cities. On consideration of energy self-reliance, environmental concerns, affordability, employment and safety these modes have a vital role to play. Non-motorized transport modes have continued to play a vital role in country's transportation system. City size and its economic base have an appreciable impact upon the supply levels, spatial coverage, content and composition of non-motorized operations. Even the metropolitan cities having organized public bus services exhibits localized use of manually operated modes. NMT modes being labor intensive and non-fuel dependent are best suited for Indian conditions and the infrastructure requirements for their operations are minimal.

\section{F. Switch-off Vehicles during Red Light Phase and use of Advance Driver Alert System}

Meng Li, Kanok Boriboonsomsin, Guoyuan Wu, WeiBin Zhang, and Matthew Barth [14] reported that vehicles unnecessary acceleration and hard braking in response to sudden changes of traffic signals cause a significant amount of wasted energy and increased emissions. Altering a driver's behavior can potentially contribute to the reductions of vehicle energy/emissions. They proposed an advanced driving alert system that provides traffic signal status information to help drivers avoid hard braking at intersections.

The high percentage of fuel wasted at signalised intersections is due to running engines while waiting for the signal to turn green. This is in spite of Petroleum Conservation Research Association's (PCRA), India continuous awareness program through print and electronic media to switch off the engines of vehicles if the waiting time is more than 14 seconds. The vehicle 
drivers need to be sensitized about the grim situation and the little contributions they can make to improve it.

Jou Rong-Chang, Hensher David, Wu Yuan-Chan, Liu Jin-Long[15] reported that the willingness-to-accept in time compensation for turning off the idling engine of motorcycles at red lights in Taiwan as part of a campaign to reduce $\mathrm{CO} 2$ emissions produced by vehicles, in early 2007. Taiwan passed the idling stop policy for all vehicles except motorcycles. They reported how much time a motorcyclist is willingness-to-accept when the engine is turned off while stopping at traffic lights. A choice experiment was designed and implemented to estimate how much time compensation motorcyclists are willing-to-accept in return for compliance with the new policy. Results show that the median willingness-toaccept time is $49.17 \mathrm{~s}$ with a cycle length of $150 \mathrm{~s}$.

\section{G. Catch Them Young}

Traffic education is a very important tool in achieving the traffic discipline. Traffic education needs to be imparted at school level so that the habit of following rules and discipline is inculcated at a very tender age. If the children are alerted of ill-effects of enhanced usage of motorized modes they can to quite an extent impress upon their parents to optimize the usage of personalized motorized transport.

\section{H. Construction of Round about, Flyover instead of Signalised Intersection}

Srinivas Mandavillia, Margaret J. Rysb, Eugene R. Russella [16] reported in their research that traditional intersections force vehicular traffic to slow down and stop in varying patterns and contribute to the increase in vehicular emissions. Modern roundabouts in US have enhanced the performance and safety of many intersections. There are numerous studies conducted by IIHS and various researchers, which support this fact. These modern roundabouts are not only capable of improving traffic flow but they can as well cut down vehicular emissions and fuel consumption by reducing the vehicle idle time at intersections and thereby creating a positive impact on the environment. The primary focus of their research was to study the impact of modern roundabouts in cutting down vehicular emissions. Six sites with different traffic volume ranges, where a modern roundabout was replaced stop-controlled intersection, were chosen for the study. The operation of the roadways at the intersection was videotaped and the traffic flow data was extracted from these tapes and analyzed using SIDRA (signalized and un-signalized intersection design and research aid) software. The version used was aaSIDRA 2.0. The software produces many Measures of Effectiveness (MOEs) of which four were chosen for analyzing the environmental impact of roundabouts. The chosen four outputs give rate of emission of $\mathrm{HC}, \mathrm{CO}$, $\mathrm{NOX}$, and $\mathrm{CO} 2$ in $(\mathrm{kg} / \mathrm{h})$.

All the MOEs were statistically compared to determine which intersection control performed better. After comparing all the MOEs at all locations for the before and after traffic volumes, it was found that the modern roundabout performed better than the existing intersection control (i.e. stop signs) in cutting down vehicular emissions therefore creating a positive impact on the environment. It was observed that a modern roundabout can be used as a viable alternative to cut down vehicular emissions, making intersections more environmentally friendly.

CRRI study[3] employed various traffic engineering and management measures to reduce delays are at the intersections like; construction of flyovers and interchanges, turning movement restrictions, optimization of cycle timings, widening of roads, and synchronized traffic signals.

At the selected 12 intersections, except for Ashram, traffic engineering measures were employed to estimate the savings in delays, and on the basis of the savings accrued at low, medium and high volume intersections the savings at the total signalized intersections was estimated, if similar kind of remedial measures are employed there. A total of 67.78 percent of fuel savings shall be achieved as shown in Fig. 1 and a 71.12 percent savings in the economic loss shall be accrued, as shown in Fig. 2.

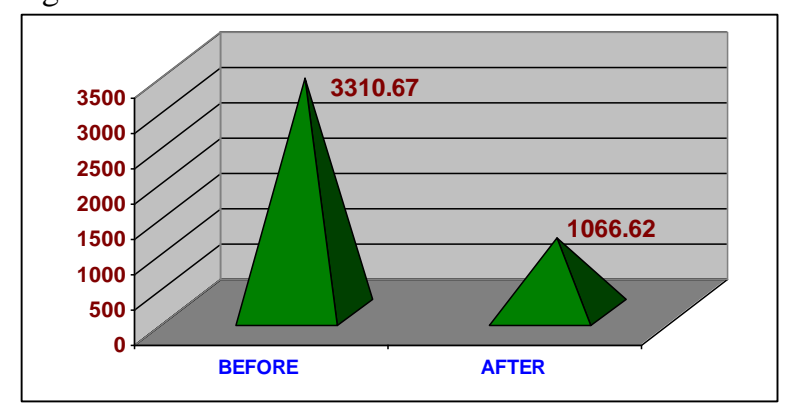

Figure 1. Annual Total Loss Before \& After Remedial Measures (In Lakh Litres)

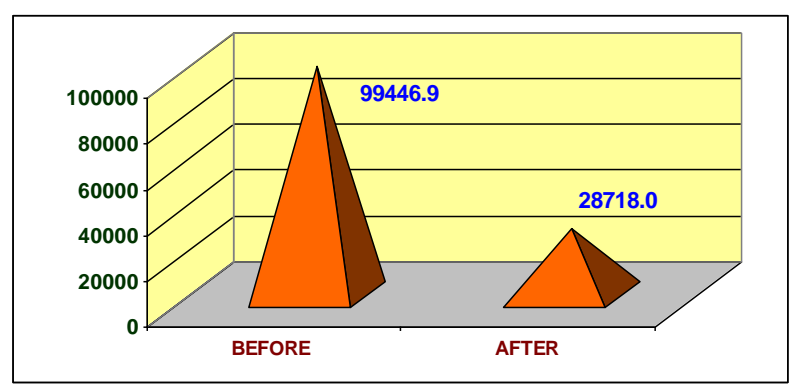

Figure 2. Annual Total Loss Before \& After Remedial Measures (In 0.1 Million Rupees)

\section{Maintaining Inter-vehicle Spacing in Congested Idling Conditions}

A. McNabola, B.M. Broderick, L.W. Gill[17] reported the study that shows the influence of inter-vehicle spacing on the in-vehicle air pollution exposure of car commuters in heavy traffic conditions both experimentally and numerically. They carried out investigation taking into the effect, on in-vehicle air pollution exposure, of maintaining a distance of approximately $2 \mathrm{~m}$ to the preceding vehicle in congested idling traffic conditions compared to that of an identical vehicle maintaining a distance of approximately $1 \mathrm{~m}$. In- 
vehicle VOC and PM2.5 concentrations revealed that a $19-31 \%$ reduction in exposure at the larger inter-vehicle spacing. Concentrations of PM2.5 were shown to be influenced to a greater degree by the preceding vehicles exhaust emissions than concentrations of VOCs. Finally, the use of the $\mathrm{k}-\mathrm{e}$ turbulence model in CFD was found to be a good method of predicting the dispersion of air pollutants from vehicles.

They used computational fluid dynamics model to calibrate the experimental data and to prediction car exposure under different conditions by varying certain key parameters. Agreement between the experimental and predicted data of $82 \%$ was achieved. The results of their study showed a significant drop in pollutant concentrations occurred within the first $2 \mathrm{~m}$ of their emission from the preceding vehicles exhaust. Also maintaining a $2 \mathrm{~m}$ distance to the preceding vehicle in realistic uncontrolled traffic conditions showed experimentally to be associated with a reduction in exposure to VOCs and particulate matter of 30-40\% compared to vehicles that maintain a difference of $1 \mathrm{~m}$. The results of their investigation show that this measure could be adopted by car commuters to significantly reduce their personal exposure to harmful air pollutants. The subsequent use of a calibrated numerical model was demonstrated that the pollution concentration drops away rapidly within the first $2 \mathrm{~m}$ of the preceding exhaust. Hence, if such a driving practice was adopted widely a resulting reduction in the health impacts of commuting by car would be observed. They also anticipated that such driving behaviour could promote a significantly higher level of traffic congestion and to determine its possible affect on increasing road safety and fuel economy.

\section{CONCLUSION}

Idling emission at intersection cause fuel and monetary loss to Nation. Therefore suitable mitigation measures are required to minimse the loss. Many authors provided very useful mitigation measures. Coordination and otimisation of signal time, strategies to conserve fuel through increased patronage of public transportation system like BRT, appropriate land use and transport policy, restraining the motorized traffic, encouraging nonmotorized modes, switch-off vehicles during red light phase and use of advance driver alert system, catching driver training at young age, construction of roundabout, flyover instead of signalized intersection, maintaining inter-vehicle spacing in congested idling conditions are observed as suitable exploratory measures to reduce the idling emission at intersection.

\section{ACKNOWLEDGMENT}

The authors wish to thank Director CRRI to publish the paper. This work was supported in part by a grant from CSIR HQ for ELSIM project under Planning Commission of India.

\section{REFERENCES}

[1] J. D. Colyar and N. M. Rouphail, "Measured distributions of control delay on signalized arterials", Transportation Research Record, vol. 1852. pp. 1-9, 2003.

[2] EPA EPA's "New Generation Mobile Source Emissions Model: Initial Proposal and Issues," Report No. EPA420-R-01-007, 2001.

[3] P. Parida and S Gangopadhyay, "Estimation of fuel loss during idling of vehicles at signalized intersections of Delhi," Technical Report, Dept. Traffic and Transportation Planning., CRRI, New Delhi, 2005

[4] P. Parida and S Gangopadhyay "Estimation of fuel loss during idling of vehicles at signalized intersections of Delhi," Journal of Indian Roads Congress, pp 61-70, August 2008.

[5] K. CHEN and L. YU, "Microscopic traffic emission simulation and case study for evaluation of traffic control strategies," Journal of Transportation Systems Engineering and Information Technology, vol. 7, issue 1, February 2007.

[6] K. Ravindra, B. K. Durai, S. Wafaa, and C. Boswell, "Comparison and evaluation of emissions for different driving cycles of motorcycles: A note," Transportation Research Part D, pp. 61-64, 2011.

[7] S. Pandian, S. Gokhale, and A. K. Ghoshal, "Evaluating effects of traffic and vehicle characteristics on vehicular emissions near traffic intersections," Transportation Research Part D 14, pp 18019, 2009.

[8] Y. Y. ZHANG, X. M. CHEN, X. ZHANG, G. H. SONG, Y. Z. HAO, and L. YU, "Assessing effect of traffic signal control strategies on vehicle emissions," Systems Engineering And Information Technology, vol. 9, issue 1, February 2009.

[9] S. L. Hallmark, K. K. Knapp, and C. D. Grant, "Evaluating speed differences between cars, light-duty trucks, and vans for emissions modeling," Journal of Transportation Engineering - ASCE 130, pp814-817, 2004.

[10] X. Feng and S. L. Chen, "An ITS method to decrease motorvehicle pollution in urban area," Journal of Traffic and Transportation. Engineering, vol. 2, no. 2, pp. 73-77, 2002.

[11] L. Yu, F. X. Qiao, and F. Soltani, "Testing and Modeling of Truck Emissions While Idling," SWUTC/06/167650-1, Center for Transportation Training and Research Texas Southern University Burne Avenue Houston, Texas 77004, 2006.

[12] R. Tiwari, R. Cervero, L. Schipper, "Driving CO2 reduction by Integrating Transport and Urban Design strategies," Cities, June 2011.

[13] L. Schipper, C. Marie-Lilliu, and R. Gorham "Flexing the link between urban transport and $\mathrm{CO}_{2}$ emissions", the Environment Division, World Bank, Paris, International Energy Agency, 2000.

[14] Meng Li, Kanok Boriboonsomsin, Guoyuan Wu, Wei-Bin Zhang, and Matthew Barth. "Traffic energy and emission reductions at signalized intersections: A study of the benefits of advanced driver information," International Journal of ITS Research, vol. 7, no. 1, June 2009

[15] J. R. Chang, H. David, Y. C. Wu, and J. L. Liu, "The willingnessto-accept in time compensation for turning off the idling engine of motorcycles at red lights in Taiwan: A short note," Transportation Research Part D, vol. 16, issue 3, pp. 251-256, May 2011,

[16] S. Mandavillia, M. J. Rysb, and E. R. Russella, "Environmental impact of modern roundabouts," International Journal of Industrial Ergonomics, 38, pp135-142, 2008.

[17] A. McNabola, B. M. Broderick, and L. W. Gill, "The impacts of inter-vehicle spacing on in-vehicle air pollution concentrations in idling urban traffic conditions," Transportation Research Part D: Transport and Environment, vol. 14, issue 8, pp. 567-575, December 2009,

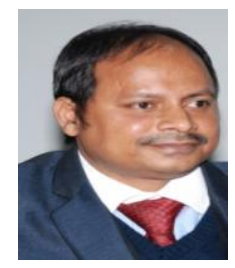

Ravindra Kumar earned his PhD (Engineering) at Edinburgh Napier University (UK) and a Master's degree (Engineering) at the University of Roorkee (now Indian Institute of Technology). He has worked for the premiere Central Road Research Institute India for the last 15 years and is a Principal Scientist in the Transport Planning department. His current research focuses on transportation and road network planning, evaluating and mitigating the environmental impacts assessment of road transport on urban air quality, with a special focus on rehabilitation and resettlement planning, real-world driving cycle and vehicular emission using advanced instruments and developing emission factors based on onboard, micro 
simulation and chassis dynamometer. He is supervising a number of under- and postgraduate project students, besides research and consultancy research.

$\mathrm{He}$ is life member of Indian Road Congress, member of CILT UK. He has completed over 20 sponsored research and consultancy projects. She has published more than 40 research papers in various journals and presented at national and international conferences

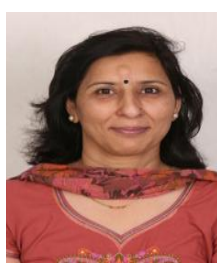

Dr Purnima Parida has done her PhD (Planning) from University of Roorkee and Master from SPA Delhi. She is a Principal Scientist and Head at the Transportation Planning Division of Central Road Research Institute, New Delhi, India. Some of the significant projects handled by Her research includes the development of qualitative and qualitative Level of Service Models for Sidewalks, Estimation of Energy Loss due to Congestion, Development of Parking Norms for Residential and Commercial Areas, and connectivity of an airport terminal with the city transport system. For her work in planning for pedestrian facilities, she was invited by the World Bank to deliver a presentation in the Transforming Transportation workshop. She has received the IRC Medal for her work on Estimation of Fuel Loss during Idling of Vehicles at Signalized Intersections in Delhi. She is a member of Urban Roads, Streets \& Transport Committee (H-8 committee) of Indian Roads Congress. She has completed over 30 sponsored research and consultancy projects. She has published more than 70 research papers in various journals and presented at national and international conferences.

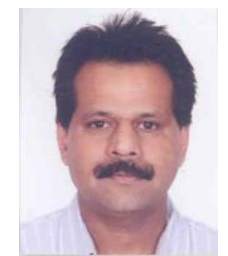

Devesh Tiwari completed his master in 1991 from University of Roorkee and earned his Phd from University of Roorkee, India. He is a Principal Scientist and at Pavement Evaluation Division of Central Road Research Institute, New Delhi, India. He has twenty years work experience in field of Development of pavement maintenance management system, Pavement data management and modelling, Pavement evaluation, maintenance and rehabilitation needs, Pavement technical audits, Road construction and quality control, Pavement failure investigations, Pavement material testing and characterization, Pavement design and Traffic engineering.

He has Received KHOSLA RESEARCH AWARD of University of Roorkee (Now IIT Roorkee), India for a research paper published in " Indian Highways ", dated May, 1987. He is receipent of COMMENDATION CERTIFICATE of Indian Roads Congress (IRC), India for a research paper published in HRB, Number 45, 1991

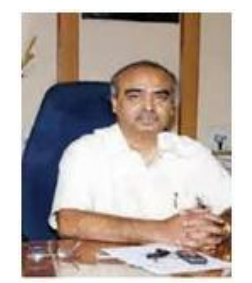

Dr S. Gangopadhyay has graduated in Civil Engineering (B.E.) from

University of Calcutta and obtained post graduate degree in Transportation System Engineering (M. Tech) from IIT, Kanpur. Dr Gangopadhyay obtained M.Sc.E \& Ph.D from the University of New Brunswick, Canada under Commonwealth Scholarship Plan.

Dr. S. Gangopadhyay joined as Scientist "B" at CRRI in 1979 and became Director Grade Scientist holding the position of Scientist G in 2005. Prior to taking over as Director, he was Head of Traffic \& Transportation planning Division at CRRI. He has more than 32 years experience in area of Traffic Engineering \& Transport Planning, Regional and Urban Travel Demand Modeling Traffic Flow Theory and Capacity Analysis, Road Traffic Safety, Urban Traffic Congestion and Environmental Impact of Road Transport. He has coordinated wide range of traffic and transportation studies covering many cities in India.

He has successfully carried out a number of significant projects i.e., Comprehensive Traffic and Transportation Study for Mumbai, Surat, Nagpur, Amaravati, Nagpur \& Aizwal; Urban Road Traffic and Air Pollution in Major Metropolitan Cities in India; Evaluation of Benefits after Implementation of Delhi Metro and Application of Intelligent Transport System in Delhi.

Dr. Gangopadhyay is a Member of Technical sub group of Delhi Development Authority and in many other committees of Delhi and Central Government.He is also Chairman of IRC, IMRA, committee and Chairman of IRC, Materials Acceredition Committee and life member of Institute of Urban Transport (India). Dr. Gangopadhyay has published more than 55 research papers and about 50 technical reports. $\mathrm{He}$ has also guided a number of Ph.D and M.E. students and has visited Canada, USA, Australia, Italy and Sri Lanka. 